\title{
FORMAÇÃO E CERTIFICAÇÃO EM MASSA E ABORDAGENS DO MULTICULTURALISMO E DAS COMPETÊNCIAS NA EDUCAÇÃO A DISTÂNCIA: IMPLICAÇÕES AO TRABALHO DOCENTE
}

\author{
João dos Reis Silva Júnior ${ }^{1}$ \\ Tânia Barbosa Martins ${ }^{2}$ \\ Universidade Federal de São Carlos (UFSCar)
}

\begin{abstract}
RESUMO
O objetivo é compreender a suposta tensão na expansão da educação a distância $(\mathrm{EaD})$ entre um sistema tecnológico de formação e certificação em massa e o respeito às necessidades individuais e diversidades culturais e as consequências decorrentes para o trabalho docente. Apresenta-se as interpretações sobre a EaD oriundas do paradigma da sociologia industrial e dos modelos de produção flexíveis, mediadas pelo uso das Tecnologias de Informação e Comunicação (TIC) e pelas influências das abordagens do multiculturalismo e das pedagogias das competências. Conclui-se que a tensão entre formação e certificação em massa e o respeito às diversidades culturais é apenas aparente; uma suposta tensão, já que as propostas de educação destas abordagens negligenciam o conhecimento, promove e reforça a formação em massa, consequentemente, torna secundário o papel do professor e prioriza o surgimento e consolidação do tutor como mero apêndice do processo educacional.

Palavras-chave: Educação a Distância; Multiculturalismo; Pedagogia das Competências; Trabalho Docente.
\end{abstract}

\section{FORMATION AND CERTIFICATION IN MASS AND APPROACHES OF MULTICULTURALISM AND OF THE COMPETENCES IN THE DISTANCE EDUCATION: IMPLICATIONS TO THE TEACHER'S WORK}

\begin{abstract}
The objective is to understand the supposed tension in the expansion of the distance education $(\mathrm{EaD})$ between a technological system of formation and certification in mass and respect to the individual needs and cultural diversities, and the consequences for the teacher's work. It presents the interpretations about EaD originating from of the paradigm of the industrial sociology and of the flexible production models, mediated by the Information and Communication Technology (TIC) and by influence of the approaches of the multiculturalism and competence's pedagogy. It is concluded that the tension between formation and certification in mass and the respect to the cultural diversities is only apparent, a supposed tension, since the proposal of education of these approaches neglect the knowledge, promotes and reinforces the formation in mass, consequently, becomes secondary the role of the teacher and prioritizes the emergence and consolidation of the tutor as a mere appendage of the educational process.

Keywords: Distance Education; Multiculturalism, Competence's Pedagogy; Teacher's Work.
\end{abstract}




\title{
Introdução
}

$\mathrm{Na}$ atualidade, a educação a distância (EaD) se apresenta como um dos temas de maior interesse da comunidade educacional científica. Permeada pelo fetiche que as tecnologias de informação e comunicação (TIC) despertam, a EaD é concebida como o meio para promover a democratização/expansão do ensino e a transformação social via educação.

No entanto, o interesse por parte significativa de pesquisadores por esse tema não reduziu as dificuldades de encontrar uma definição consensual de educação a distância. Aretio (2002) relata que a falta de entendimento em torno da definição de educação a distância e a grande diversidade de propostas metodológicas, estruturas, projetos, modelos institucionais, grupos destinatários etc., estão entre os principais fatores que contribuem para os pesquisadores abandonarem a intenção de definir melhor a educação a distância.

A busca para compreender a essência e os traços fundamentais da educação a distância permitem constatar que, em geral, as definições e teorias na educação a distância não são unânimes, mas são elaborados com base em paradigmas teóricos que se estendem desde a perspectiva da sociologia industrial à de modelos mais flexíveis de influência pósmoderna.

A questão que se nos impõe é compreender a tensão existente entre a democratização/expansão do acesso/oferta e a garantia das diferenças e necessidades individuais num sistema de formação e certificação em massa e as consequências para a formação e o trabalho docente. Para tanto, apresenta-se as definições e interpretações a respeito da $\mathrm{EaD}$ e a relaciona com a Pedagogia das Competências (de influência multicultural).

\section{As Abordagens Teóricas e Metodológicas na EaD}

Belloni (2003) relata que a definição de EaD que causou mais polêmica é a de Otto Peters oriunda da sociologia industrial. Otto Peters configura a EaD como um modelo predominantemente industrial:

\begin{abstract}
Educação a distância é um método de transmitir conhecimento, competências e atitudes que é racionalizado pela aplicação de princípios organizacionais e de divisão do trabalho, bem como pelo uso intensivo de meios técnicos, especialmente com o objetivo de reproduzir material de ensino de alta qualidade, o que torna possível instruir um número maior de estudantes, ao mesmo tempo, onde quer que eles vivam. É uma forma industrializada de ensino e aprendizagem (PETERS, 1983, p.111 apud BELLONI, 2003, p. 10).
\end{abstract}

A partir de 1970, Otto Peters analisa as características da EaD com base em analogias com o processo de produção industrial fordista, existente no Ocidente, particularmente, a partir da $2^{\mathrm{a}}$ Guerra Mundial. Esse modelo apresenta as seguintes características: racionalização, planejamento, padronização, mecanização, linha de montagem, divisão do trabalho, produção em massa, concentração dos recursos e centralização administrativa.

Segundo Otto Peters, a EaD é uma forma de estudo complementar à era industrial e tecnológica, portanto, a $\mathrm{EaD}$ é uma modalidade fordista-taylorista de educação. Como resultado, o processo pedagógico na $\mathrm{EaD}$ é reestruturado com base em três características principais: racionalização, divisão do trabalho e produção em massa. Somadas a essas características, estão outras estratégias fordistas-tayloriosta na $\mathrm{EaD}$, como a criação de 
provedores altamente especializados e centralizados que operam em âmbito nacional, com distribuição centralizada de cursos e programas, concebidos por pequeno grupo de especialista e destinado a um mercado de demanda massificada.

A aplicação dos princípios do modelo fordista-taylorista na $\mathrm{EaD}$ provocou um forte debate e contribuiu para ampliar as abordagens relacionadas à educação com o intuito de superar o próprio paradigma da sociologia industrial. A Universidade Aberta do Reino Unido e os representantes da $\mathrm{EaD}$ na Austrália participaram intensamente do debate e defenderam a necessidade de novos referenciais na EaD (BELLONI, 2003. p. 10).

A partir da década de 1980, a reestruturação econômica, resultado das recessões econômicas, e inflação impuseram um amplo processo de reformas dos Estados e de suas instituições. Nessa fase do capitalismo, o fordismo-taylorismo, que se baseava na produção em massa para amplo mercado, não é mais suficiente nas sociedades com alto nível de competição. Surgiram, então, novos modelos de produção industrial que passaram a utilizar intensamente as novas possibilidades oferecidas pelas novas tecnologias de comunicação e informação.

O pós-fordismo, identificado com o modelo japonês de produção sugere estratégias de alta inovação dos produtos, variedade na produção com base no uso intenso das tecnologias, da flexibilização da produção, da mão de obra mais qualificada, da responsabilização do trabalhador e supressão da tradicional divisão do trabalho e do rígido controle.

A necessidade da $\mathrm{EaD}$ se adequar às novas exigências sociais também resultou na elaboração de abordagens oriundas do modelo pós-fordista. No plano da $\mathrm{EaD}$, os princípios do pós-fordismo são representados por mais exigências de qualificação dos trabalhadores, flexibilização e diversificação dos cursos, que podem ser oferecidos de modo presencial, a distância e/ou semipresencial. Além disso, existiriam outros elementos, tais como atender às necessidades dos alunos. Daí se prolifera inúmeros cursos de formação inicial, continuada, treinamentos, etc.

Segundo Belloni (2003), essas transformações permitem afirmar que no paradigma pós-fordista, a $\mathrm{EaD}$ é considerada não um modelo do setor secundário (industrial), mas uma atividade do setor terciário. Desse modo, a diferença entre o paradigma fordistataylorista e o pós-fordista é a ênfase do segundo na demanda, ou seja, nas necessidades e exigências do estudante, considerado consumidor. É essa característica que coloca a EaD como uma atividade do setor terciário, de serviços. Em consequência da influência do modelo pós-fordista, a EaD sofre alteração em sua definição e conceito. Em tempos de transformações do sistema capitalista o conceito de aprendizagem aberta (AA) ou aprendizagem aberta e a distância (AAD) supostamente seriam mais apropriados, sobretudo, na visão dos organismos internacionais (BELLONI, 2003, p.34).

A aprendizagem aberta é definida, fundamentalmente, por critérios de abertura, relacionados ao acesso, lugar e ritmo de estudo dos alunos, ou seja, conforme a demanda e não mais em função da oferta. Com a aprendizagem aberta a distância (AAD) e a aprendizagem aberta (AA), a EaD encontra terreno fértil para se desenvolver. Assim, a $\mathrm{AAD}$ e a $\mathrm{AA}$ constituem dois aspectos do mesmo fenômeno. O primeiro refere-se mais à modalidade de educação e a seus aspectos institucionais e operacionais, considerando, particularmente o ensino, enquanto o segundo se refere aos modos de acesso:

A relação entre os conceitos de aprendizagem aberta e aprendizagem a distância é mais complexa. Aprendizagem aberta tem essencialmente dois significados: de um lado, refere-se aos critérios de acesso aos sistemas educacionais ("aberta" como equivalente à ideia de remover barreiras ao livre acesso à educação e ao treinamento); de outro lado, significa que o 
processo de aprendizagem deve ser, do ponto de vista do estudante, livre no tempo, no espaço e no ritmo (time-free, place-free e pace-free). Ambos os significados estão ligados com uma filosofia educacional que identifica abertura com aprendizagem centrada no aluno (TRINDADE, 1992, p. 30 apud BELLONI, 2003, p.30).

A aprendizagem aberta e a distância (AAD) tem como princípio orientador a centralidade no aprendiz. Isso significa formas de aprendizagem mais flexíveis, abertura dos sistemas e maior autonomia do aluno.

Essa nova concepção (conceito) de educação (a distância) é parte da política do Estado implementada com base nas recomendações dos órgãos de fomento, como o relatório elaborado pela Organização das Nações Unidas para a Educação, a Ciência e a Cultura (Unesco) de autoria da Comissão Internacional sobre Educação, coordenada por Jacques Delors (2006), sobre a educação para o século XXI. Esse relatório afirma a necessidade de construir novas relações com o conhecimento, fundadas no desenvolvimento das competências, as quais estariam assentadas em quatro pilares: aprender a conhecer, aprender a fazer, aprender a conviver e aprender a ser. Ressalta ainda, a necessidade de aperfeiçoar e reforçar o papel das TICs no processo de ensino e aprendizagem.

\section{Multiculturalismo e a Pedagogia das Competências}

O conceito atual de multiculturalismo está atrelado ao sentido que a sociedade contemporânea lhe atribuiu com a chamada globalização da economia desde o mundo pós $2^{\text {a }}$ Guerra Mundial. O multiculturalismo se concretiza a partir de diferentes correntes teóricas, diversos significados, apresentando-se como um conceito polissêmico, atualmente está em destaque em função da globalização da economia. O processo de globalização da economia não é algo novo e recente, remonta à expansão europeia do século XV e XVI com o processo de intercâmbio de mercadorias da política econômica mercantilista dos países europeus e da política colonialista. O que poderia explicar o surgimento e a intensificação do contato e da convivência entre culturas diferentes que, desde então, produziram sociedades multiculturais.

O reconhecimento da multiculturalidade iniciou-se primeiramente nos Estados Unidos e no Canadá, seguidos da Europa nas décadas de 1960 e 1970. As discussões nos Estados Unidos sobre a presença multicultural na sociedade americana se iniciaram como uma:

Questão educacional e curricular quando grupos culturais subordinados as mulheres, os negros, as mulheres e homens homossexuais iniciaram uma forte crítica à estrutura do currículo universitário porque o caracterizara como expressão do privilégio da cultura branca, masculina, europeia e heterossexual. (SILVA, 2003 apud ARAÚJO, 2009, p. 67).

Portanto, foi definida especialmente como uma abordagem educativa como forma de responder à crescente diversidade cultural e à complexa sociedade produzida pela mundialização.

Conforme Silva (2005, p.85), não se pode pensar o multiculturalismo apenas em função da diversidade cultural, pois a própria diversidade cultural é fabricada como instrumento de homogeneização, com um claro caráter ambíguo. Os próprios meios de comunicação de massa se convertem em instrumentos de expressão de grupos dominantes. Desse modo, não se podem separar questões culturais de questões de poder. De tal modo que a cultura do multiculturalismo se transforma, em questão de educação, formação ou 
instrução, em outros termos, como fator educativo, cabe ao multiculturalismo incentivar uma aceitação passiva do relativismo cultural por si mesmo, quando na verdade a noção de multiculturalismo é uma produção teórica originada dos países centrais. O "respeito" e a "tolerância" propagados pelo multiculturalismo implicam certa concepção implícita de superioridade cultural e de essencialismo cultural, além de uma suposta convivência harmoniosa que subjuga as reais condições históricas e culturais em que as diversas culturas estão inseridas.

Uma consequência é a noção de igualdade de oportunidade, especialmente escolar, que pressupõe uma diversidade baseada nas capacidades e nos desenvolvimentos diferenciados. Essa diversidade pressupõe um ponto único e final, um percurso comum a que todos devem percorrer para se chegar ao topo, uma universalização das relações sociais capitalistas, ou seja, a igualdade de oportunidades encobre a ideologia de assimilação da cultura dominante que busca um critério e padrão único de desempenho, como as avaliações de aprendizagem e de instituições escolares dos organismos internacionais como da Unesco e da OCDE (Organização para a Cooperação e Desenvolvimento Econômico).

Nessa concepção não crítica do multiculturalismo tem-se, ainda, a valorização do aspecto individual, particular e fragmentado da noção de cultura que segmenta e hierarquiza a diversidade cultural. Então, o multiculturalismo está atrelado à questão de poder e dos problemas de governabilidade, cujo objetivo educacional ou multicultural é criar condições na diversidade para o fortalecimento do processo de mundialização.

O multiculturalismo do pós $2^{\text {a }}$ Guerra Mundial, que serviu de instrumento para amenizar a situação de desigualdade social, miséria, violência e exploração, resultantes de décadas de exploração dos países colonizadores, contribuiu para o fortalecimento das diversidades culturais e o fortalecimento da noção de nacionalismo, culminando com a rebelião dos povos subjugados e a conquista de suas independências nacionais. Entretanto, não alterou a essência da situação, já que a reconfigurou com base na ideologia do multiculturalismo vinculado à "globalização". Assim, esses povos se inseriram anomalamente na economia e na cultura dominante por meio da mundialização do capital ou do comércio mundial. Os países, especificamente, os países descolonizados, não conseguiram ainda produzir uma cultura nacional ou cívica própria, dadas as dificuldades e a pobreza generalizada criada pelo próprio sistema em que estão inseridos. Conforme Hall (2009, p.57):

É um sistema de con-formação da diferença, em vez de um sinônimo conveniente de obliteração da diferença. Este argumento torna-se crucial se considerarmos como e onde as resistências e contra estratégias podem desenvolver com sucesso.

A descolonização, que produziu a formação dos Estados Nacionais e a valorização da diversidade cultural, não escapou às interdependências mundiais, sendo que a soberania nacional se encontra atrelada ao caráter universal e contraditório do capitalismo. E essa diversidade ou diferença cultural implicam desigualdades e instabilidades de ordem econômica, política, étnica, cultural e religiosa. O multiculturalismo tende a criar uma cultura mundializada, cuja tendência dominante é a homogeneização, mas, simultaneamente, com efeitos diferenciadores dentro do sistema.

O sistema é global, no sentido de que sua esfera de operação é planetária. Poucos locais escapam ao alcance de suas interdependências desestabilizadoras. Eles têm enfraquecido significativamente a soberania nacional e o "raio de ação" dos Estados-nação (os motores das primeiras fases da globalização), sem deslocá-los completamente. O sistema, 
entretanto, não é global, se por isso se entende que o processo é de caráter uniforme, afeta igualmente todos os lugares, opera sem efeitos contraditórios ou produz resultados iguais no mundo inteiro. Ele continua sendo um sistema de desigualdades e instabilidades[...]

Juntamente com as tendências homogeneizantes da globalização, existe a "proliferação subalterna da diferença". Trata-se de um paradoxo da globalização contemporânea o fato de que, culturalmente, as coisas pereçam mais ou menos semelhantes entre si (um tipo de americanismo da cultura global, por exemplo). Entretanto, concomitantemente, há a proliferação das "diferenças". O eixo "vertical" do poder cultural, econômico e tecnológico parece estar sempre marcado e compensado por conexões laterais, o que produz uma visão de mundo composta de muitas diferenças "locais", as quais o "global-vertical" é obrigado a considerar. (HALL, 2009, p. 57).

O multiculturalismo, como prática política e educacional, influenciou a concepção educacional da Unesco no mundo pós $2^{\mathrm{a}}$ Guerra Mundial, num contexto marcado pelo processo de descolonização e numa proposta educacional pautada pela noção de "aprender a ser" e pelo "aprender a conviver" nos moldes da pedagogia das competências, que produz um suposto respeito à diversidade cultural.

A origem da pedagogia das competências surge a partir dos diagnósticos e relatórios de organismos internacionais sobre o estado da arte dos sistemas educacionais do mundo. Seus diagnósticos são universais e genéricos, não se atendo às especificidades dos sistemas dos diversos países, mas o influenciando de maneira significativa. Um dos primeiros é o relatório produzido pela Unesco de 1972, denominado Relatório Edgar Faure "Aprender a Ser" em que se constatava uma nova situação mundial com o desenvolvimento da ciência e tecnologia e a necessidade de uma educação adequada a esta nova realidade social. Nas palavras de René Maheu, diretor geral da Unesco, o relatório tem uma aspiração de objetividade e que a comissão elaborou "um inventário da educação atual e definiu uma concepção global da educação de amanhã que, sem dúvida, jamais foi objeto de uma formulação tão completa" (p. 13). Embora, o próprio Edgar Faure diga que o relatório seja fruto de um trabalho neutro, de ideias formuladas de forma autônoma e livre, ele reconhece:

A existência duma comunidade internacional que, sob a diversidade das nações e de culturas, das opções políticas e dos níveis de desenvolvimento, se exprime pela unidade de aspirações, de problemas e de tendências e pela convergência para um mesmo destino. (FAURE, 1974, p. 10)

Dessa forma, apresenta uma proposta genérica de educação em torno do sentido do próprio relatório: "aprender a ser", como solidariedade entre os povos; a crença na democracia; na expansão do homem em toda sua complexidade; e na formação do homem, ou seja, não se trata mais de adquirir conhecimentos definidos, mas de uma educação adequada para toda uma vida.

O segundo relatório da Unesco de 1996, denominado Relatório Jacques Delors, "Educação: um tesouro a descobrir", parte do pressuposto da globalização das relações econômicas e culturais, chamado de arena global, um novo mundo num clima de incertezas e apreensão que necessita de um enfoque verdadeiramente global dos problemas ainda mais angustiantes. A preocupação principal do relatório é com o "desenvolvimento humano mais harmonioso, mais autêntico, de modo a fazer recuarem a pobreza, a exclusão social, as incompreensões, as opressões, as guerras...". (DELORS, 1998, p. 11). O relatório 
Jacques Delors mostra preocupações semelhantes àquelas do relatório Edgar Faure, que acrescenta, ao aprender a ser (humano), o aprender a conviver (com o outro humano). Diz que, apesar de ser uma tarefa ainda impossível, um dos objetivos foi "ultrapassar o obstáculo da extraordinária diversidade de situações no mundo, conseguir análises válidas para todos e obter conclusões igualmente aceitáveis por todos". Acrescenta que:

A comissão esforçou-se por elaborar os seus raciocínios num quadro prospectivo dominado pela globalização por selecionar questões importantes e que se colocam em qualquer parte do mundo, e por traçar algumas orientações válidas, tanto em nível nacional como mundial (DELORS, 1998, p. 12).

Em ambos os relatórios, a preocupação se desloca do conhecimento propriamente dito para as abordagens ativistas multiculturalistas e das competências cognitivas e sociais. Em geral, os conhecimentos do ensino formal se orientam em torno do "aprender a conhecer" e do "aprender a fazer", desconsiderando outros aspectos importantes do processo de ensino e de aprendizagem. E tanto o conhecer como o fazer se tornam insuficientes no contexto mundial da globalização com todas as suas vicissitudes. $\mathrm{O}$ relatório Jacques Delors parte do argumento de que as indústrias necessitam de pessoas que "saibam" e que "saibam fazer", conhecimentos indissociáveis, mas, igualmente de certas qualificações pessoais, as quais denominam de competências, tais "como comportamento social, aptidão para o trabalho em equipe, a capacidade de iniciativa, o gosto pelo risco" (DELORS, 1998, p. 94). Esta abordagem produz o estatuto da qualificação individual do trabalhador, exigido pelas indústrias e pelo setor de serviços em pleno desenvolvimento. As competências saem da esfera objetiva dos conhecimentos e entram em "qualidades muito subjetivas, inatas ou adquiridas, muitas vezes denominadas 'saber-ser" pelos dirigentes empresariais, se juntam ao saber e ao saber-fazer para compor a competência exigida" (DELORS, 1998, p. 94). As competências pressupõem qualidades humanas que o ensino convencional não ensina nem transmite como cultivar relações sociais, interpessoais. Esta competência é o que o relatório denomina de "aprender a viver junto" ou, simplesmente, "conviver", inclusive, em função de um mundo com tantos conflitos e violências. A última competência é semelhante à proposta pelo relatório Edgar Faure, "aprender a ser" que pressupõe o desenvolvimento completo do individuo, inteligência, sensibilidade, espiritualidade, criatividade, responsabilidade etc., com o intuito de desenvolver a pessoa e sua autonomia sadia com capacidade de discernimento, humanidade, imaginação, sentimento, próprio do ser humano.

Eis as noções multiculturais como princípio na pedagogia das competências no âmbito da Unesco que serviram de parâmetro para a educação de diversos países do mundo e suas respectivas reformas educacionais e curriculares. Trata-se de uma concepção de educação e currículo que tende a negligenciar os conteúdos escolares e o conhecimento propriamente dito em prol das competências ("aprender a conviver" e "aprender a ser"). Os conhecimentos, que são relativamente universais, foram substituídos ou complementados pelas competências como suposta individualização e respeito à diversidade cultural dos países do mundo, mas, igualmente, universais do ponto de vista das exigências do mercado de trabalho capitalista como fator de qualificação profissional. As competências foram introduzidas em função das necessidades de qualificação profissional, exigidas pelas indústrias e pelas teorias da administração de empresa, nos moldes do padrão flexível de produção industrial.

Tais competências criam uma nova estratégia empresarial e educacional para introduzir um parâmetro comum de exigências diversas, específicas, individuais, mas universais do ponto de vista empresarial, criando um molde comum para lidar com a 
diversidade cultural num mundo globalizado. É a maneira pela qual se estabelece uma inserção global e única dos organismos internacionais nas economias regionais do mundo por meio da educação, criando um sistema de educação global, dissimulado de respeito à diversidade, de modo a favorecer ainda mais o processo imperialista de mundialização do capital.

Nesse sentido, a OCDE elaborou uma série de pesquisas e avaliações dos sistemas educacionais dos países membros por meio do PISA (Program International for Student Assessment - Programa Internacional para a Avaliação de Estudantes), numa perspectiva de educação comparada, gerando relatórios anuais globais comparativos (Education at a glance), a partir dos rendimentos básicos (leitura, matemática e ciências) com bases em referenciais da pedagogia das competências. A ideia é ranquear os países e criar um padrão comum de desenvolvimento dos seus sistemas de ensino e buscar indicadores para avaliar os resultados quantitativos. Desse modo, os relatórios têm justificativas de caráter econômico, às vezes disfarçados de linguagem pedagógica. Conforme Sacristán (2011):

Estamos diante de uma proposta que tem a pretensão de tornar as competências básicas norma universal a ser seguida, em todos os países e idades (lifelong learning). Essa extrapolação transforma as competências em instrumentos normativos a partir dos quais se busca a convergência dos sistemas escolares, tornando as competências referência para a estruturação dos conteúdos de um currículo globalizado (SACRISTAN, 2011, p. 24).

Sacristan (2011, p. 24) acrescenta que é explícita a intenção da OCDE em transformar as competências em algo possível de se ensinar e aprender. O relatório Jacques Delors considera que esse um tipo de conhecimento não se ensina na escola convencional. Sobre o propósito dos organismos internacionais, especificamente, a Unesco e a OCDE, em matéria de políticas educacionais e da estratégia de guiar a educação por meio das competências, convém destacar novamente as palavras de Sacristan (2011):

Nos últimos anos, além do intercâmbio de universitários, se tomou uma série de medidas para homologar títulos e profissões e, em um plano mais geral, alcançaram-se alguns objetivos aceitos por todos, ressalvada a diversidade cultural. Mas para a UE [União Europeia] definir um currículo comum é difícil diante dessa diversidade; então, somente é possível confluir para o que pode ser compartilhado. Recorrer às competências é útil para deixar de lado os conteúdos e se manter num nível de coincidências formais, convertendo-a na bandeira visível da convergência dos sistemas educacionais, sem se intrometer na "cultura" de cada país. Essa é uma das razões da entrada da nova linguagem [competências] no cenário das políticas educacionais (SACRISTÁN, 2011, p.30).

As competências divulgadas pela OCDE no relatório de 2010 são igualmente as mesmas do discurso do mercado de trabalho e da competitividade econômica, em torno das questões da cidadania, da coesão social e do emprego ou empregabilidade:

1) Comunicação em língua materna

2) Comunicação em língua estrangeira

3) Competência em matemática e competências básicas em ciência e tecnologia

4) Competência digital

5) Aprender a aprender 
6) Competências sociais e cívicas

7) Sentido de iniciativa e cívicas

8) Consciência e expressão cultural

A tensão entre o global/universal e o local/particular apresenta o mesmo sentido do multiculturalismo com o processo de globalização excludente ou diversificado. Este sentido é efetivado com a pedagogia das competências por meios de organismos internacionais e suas pesquisas educacionais, tornando o multiculturalismo uma política efetivamente educacional. A educação a distância como modalidade de ensino, conjuga a realização de um projeto de formação e certificação em massa pelo uso dos recursos tecnológicos e a preocupação político-pedagógica com a diversidade cultural por meio das pedagogias das competências.

\section{As Novas Exigências e Relações de Trabalho Docente}

A análise sobre a educação a distância no Brasil, entre os anos de 1960 a 1980, se aproxima da percepção de Otto Peters, pois nesse período a educação tinha como pressupostos os resquícios da educação tecnicista, sob o jugo ideológico da teoria do Capital Humano. Nessa concepção estritamente fordista-taylorista, a finalidade era a formação, ainda que aligeirada, para o mercado de trabalho. As tecnologias, com destaque para o rádio e a TV permitiam um processo de certificação em massa com propostas de formação padronizada, universal e homogênea. Destacam-se as experiências transmitidas pela TV como o Telecurso de Segundo Grau, criado pela Fundação Roberto Marinho, atualmente denominado de Telecurso 2000. Os recursos tecnológicos estavam no centro do processo educativo e reinavam como fator objetivo e mediador por excelência na aprendizagem. Essa concepção, que tem como finalidade e foco o ensino e como mediação a tecnologia, subsumiu a importância da figura do professor, que se apresenta como mero instrumento subjacente à máquina. A transmissão do conteúdo continua prioritária no processo pedagógico e educativo, mas afastado das atribuições docentes. A função do professor reduzia em preparar passivamente as condições de transmissão do conteúdo. Além disso, os conteúdos eram programados, considerando o uso de uma sequência de atividades técnicas e objetivas, dependentes dos recursos tecnológicos. A educação a distância se aproximava da organização de uma fábrica fordista-taylorista, com a ênfase na eficiência e racionalidade, associada às necessidades econômicas e políticas de um regime militar-ditatorial.

Atualmente, ainda há resquícios das características do modelo fordista-taylorista na EaD. Aliás, o fordismo-taylorismo não é incompatível com os modelos de produção flexível, na verdade, não se pode dizer que com esse modelo esteja superado o fordistataylorista. Em geral, o que se tem é uma produção mista, uma complementariedade, não uma contraditoriedade. Assim, no Brasil, os sistemas de educação a distância, dentre outros aspectos, apresentam-se como um sistema de formação em massa, com modelos padronizados, baseados na divisão do trabalho, racionalização e centralização administrativa.

A aprendizagem aberta (AA) e aprendizagem aberta a distância (AAD) também descaracteriza a função do professor ao deslocar o foco do ensino para a aprendizagem e apresentar como principais fatores educacionais o aluno e suas particularidades psíquicas, afetivas, emotivas, sociais, culturais etc. As TICs mantêm-se como principais fatores que permitem a existência da $\mathrm{EaD}$, mas agora como subsidiárias de uma teoria pedagógica refinada e elaborada. Se o foco não é mais o ensino mediado pela máquina, que deslocava o papel do professor, agora, com o foco na aprendizagem, o professor secundariza-se no 
processo de ensino-aprendizagem e promove a emergência da figura do tutor com uma série de exigências profissionais e novas relações sociais de trabalho. No processo imediato, desaparece a figura do professor, que se afasta do conhecimento e conteúdo escolar, do cotidiano e contato direto com o discente, emergindo em seu lugar o tutor. Esse processo de produção de conhecimento configura um complexo sistema de produção e certificação em massa, sob uma nova forma de orientação que se apropria não apenas do conhecimento do trabalhador, mas de sua subjetividade (ALVES, 2000).

A função social da escola reside na transmissão de conteúdos construídos historicamente pela sociedade, sendo o compromisso é com a reprodução e produção pela classe trabalhadora da riqueza cultural e intelectual da humanidade. Daí que a mediação da direção e do conteúdo realizado pelo professor é determinante para garantir essa especificidade da educação. No entanto, cada vez mais a sintonia da pedagogia com as formulações e diretrizes divulgadas internacionalmente pelos organismos internacionais, sob o pano de fundo de um discurso de democratização e inclusão, convertem-se em verdadeiros "cavalos de troia" (ARCE, 2010, p.86). Desse modo, legitima diferentes pedagogias burguesas - Pedagogia dos Projetos, do Multiculturalismo, das Competências, do Professor Reflexivo, Pedagogia Empreendedora etc.- que têm em comum reduzir e simplificar o ato educativo em prol dos interesses hegemônicos.

Na educação convencional (presencial) e na educação a distância é evidente que as exigências profissionais e as condições do trabalho docente, estão em sintonia direta com as exigências de formação docente vinculadas aos aspectos principais destas pedagogias burguesas. No entanto, não há nenhuma diferença, essencial, nas atribuições pedagógicas entre docentes do ensino presencial e docentes da educação a distância. Por outro lado, a figura do tutor tem uma especificidade que permite questionar o próprio papel docente do tutor, ou seja, as diferentes exigências profissionais e condições de trabalho afetam de maneira ímpar e incisiva o tutor, mais do que o trabalho do professor convencional. $\mathrm{Na}$ realidade, é possível pensar ainda que as exigências profissionais e as condições do trabalho docente do tutor tendam a sucatear a profissão docente convencional em função das referidas pedagogias.

$\mathrm{Na}$ formação e no trabalho docente na $\mathrm{EaD}$, a ideia predominante é que a formação de professores supostamente ocorre na prática, como resultado das experiências pessoais dos docentes no cotidiano social e escolar. Daí que os cursos de formação de professores tendem reduzir os conteúdos escolares (os conhecimentos das áreas disciplinares) e enfatizar a importância das competências como mais propícias ao aprendizado continuado e até, pragmaticamente, à formação inicial.

Araújo (2007) demonstra que os tutores manifestam preocupações com o aspecto epistemológico, como elemento primordial para o desenvolvimento do trabalho pedagógico. Entretanto, há uma tendência no trabalho dos tutores, denominados de professores-mediadores, na perspectiva de um paradigma da racionalidade técnica. As práticas são arraigadas e fundadas exclusivamente na experiência prática e não contribuem para ultrapassar o senso comum, mesmo considerando os esforços por parte dos tutores em estudar os módulos e se aprofundar nos assuntos. Há certa superficialidade no trato com o conteúdo escolar, o que significa que os conhecimentos históricos e científicos perdem espaço para os conhecimentos advindos das experiências pessoais dos alunos e do tutor. A finalidade não é mais o conhecimento em si, mas as competências. Com o conhecimento se vai a diversidade e com as competências vem a universalidade. Conforme Araújo (2007) é perceptível o desconforto em relação ao fato de o tutor ser um generalista, assumindo a responsabilidade de todo o conhecimento focalizado no curso e organizado em módulos. Essa objetividade pode produzir a superficialidade com o conhecimento, pois, em geral, o 
tutor aprofunda os assuntos mais próximos de sua formação e, caso não tenha familiaridade com a área de conhecimento de sua tutoria, sua ação se restringe a preparar o ambiente, a buscar desenvolver as competências exigidas, que são idênticas a qualquer conteúdo. $\mathrm{O}$ tutor não se torna nem mediador dos conhecimentos, mas um facilitador do aprendizado de competências e não dos conteúdos. Todo professor é professor de algo, de algum conhecimento, nesse sentido, o tutor é um não professor, mas, simplesmente, tutor. E o que é um tutor não se sabe exatamente. Desse modo, o significado de mediação "se articula à ideia superficializada de meramente 'facilitar' a aprendizagem" (ARAÚJO, 2007, 294). Segundo Araújo há certos exageros na utilização de algumas estratégias metodológicas tais como dinâmicas e vivências que limitam o aprofundamento teórico dos assuntos dos módulos, consequentemente, limitam a compreensão da realidade social e a possibilidade de compreensão da realidade. De modo geral, Araújo (2007) menciona a existência de traços da política de formação de professores, reféns dos ditames neoliberais, que seguem os padrões mercantis e figuram no âmbito da formação aligeirada e desqualificada que se restringe ao campo da prática e contribui para rebaixar as condições de formação.

Em consequência a EaD demanda um tipo de pedagogia que enfatiza a metodologia e não o conhecimento. Ao analisar as concepções pedagógicas contemporâneas no Brasil baseadas na pedagogia do "aprender a aprender" ou "pedagogia das competências", Duarte (1998) conclui que essas pedagogias tornam secundário o conteúdo escolar e o conhecimento historicamente produzido pela sociedade, de modo a negligenciar, no processo de ensino-aprendizagem, o conhecimento e descaracterizar o papel do professor como agente mediador da cultura. Para Duarte (1998, p. 3): "cabe ao processo educativo dirigir o desenvolvimento psíquico do indivíduo e não caminhar a reboque de um desenvolvimento espontâneo e natural". E ainda, que "o professor não pode ser reduzido a um 'animador', a alguém que fornece condições para que o aluno construa por si mesmo o conhecimento" (p. 6). O ato educativo não deve valorizar as aprendizagens que o indivíduo realiza sozinho como qualitativamente superiores àquelas que o indivíduo realiza com a mediação do professor. Para Duarte a especificidade da educação reside em transmitir ao indivíduo aquilo que ele não é capaz de aprender por si só (DUARTE, 1998).

Segundo Furquim (2010), a maior parte das pesquisas compreende que a função do tutor não pode ser de um transmissor de conteúdo, mas alguém que deve estimular nos alunos à autonomia e à capacidade de aprender a aprender, lema consubstanciado pelo relatório Jacques Delors. A função do tutor relaciona-se com a questão da mediação da aprendizagem dos alunos e exige tutores com características peculiares como capacidade de seduzir, impressionar, entusiasmar e motivar o aluno com objetivo de não criar resistência ao estudo nem desistência do curso. Desse modo, o tutor deve conhecer a realidade dos alunos, suas características pessoais, sociais, familiares, escolares, entre outras, para criar permanentes diálogos e participações. O tutor deve dispor de habilidades comunicacionais para despertar simpatia e estimular a capacidade de autoaprendizagem e a postura ativa do aluno. Finaliza o autor que o tutor é a figura central no sentido de que deve contribuir para amenizar o sentimento de solidão no processo de ensinoaprendizagem, comum na EaD. É patente que o autor demonstrou que as exigências de formação docente estão atreladas às noções de competências.

Ziede (2008) pesquisou como a formação continuada realizada por uma pósgraduação contribuiu na construção da concepção de tutoria realizada por tutores do curso de graduação em Pedagogia - licenciatura na modalidade a distância da mesma instituição. A autora relata que no curso são abordados temas que se relacionam ao trabalho em equipe, à afetividade entre tutor, professor e aluno, à organização do tempo, conhecimento pedagógico, tecnológico e à capacidade para planejar estratégias de intervenção, mas, 
sobretudo, "habilidade para realizar as intervenções, tanto on-line como presenciais, pois esclarecer dúvidas, auxiliar as construções e acompanhar postagens são atividades desempenhadas diariamente" (ZIEDE, 2008, p. 170). Destaca ainda a autora que o trabalho do tutor associado ao uso das TICs e novas formas de conceber e fazer a educação mostram possibilidades privilegiadas para a formação de um novo "professor" e aluno. Têm-se então um curso de formação docente em pós-graduação que não discute a formação do ponto de vista do conhecimento, apenas metodologicamente. Além do mais é evidente a falta de conhecimento histórico e crítico sobre o conteúdo escolar e sobre a prática pedagógica dos tutores. A formação de professores ou sua capacitação em serviço condiz plenamente com a proposta de formação docente via competências, tomando como verdadeiras esta concepção e a ideia de articulação como mundo produtivo e o determinismo tecnológico.

\section{Considerações Finais}

$\mathrm{O}$ artigo buscou compreender a suposta tensão na expansão da $\mathrm{EaD}$ entre um sistema tecnológico de formação e certificação em massa e o respeito às necessidades individuais e diversidades culturais dos sujeitos, propostos e sugeridos pelas abordagens pós-modernas da pedagogia das competências, de inspiração multicultural, e as consequências decorrentes para o trabalho docente do tutor. Com essa finalidade, buscouse compreender as interpretações sobre a EaD considerando as abordagens oriundas do paradigma da sociologia industrial e a dos modelos de produção flexível, baseadas na produção flexível.

A tensão se configurou exatamente como uma suposta ou ilusória tensão, pois na realidade as propostas confluem para um mesmo ponto, ou seja, a certificação em massa com o suposto respeito às diversidades é possível no sistema de EaD somente pela negligência do conhecimento ou conteúdo escolar e pela negação da diretividade do professor, em prol das competências e do autodidatismo do "aprender a aprender". Assim as divergências são apenas aparentes entre o sistema de formação e certificação em massa, patrocinada pelo uso intenso dos recursos tecnológicos das TICs e as necessidades políticopedagógicas de considerar as diversidades individuais e culturais dos sujeitos envolvidos, tutores e alunos, patrocinados pela pedagogia das competências de inspiração multicultural.

Da mesma forma em que não há divergências, mas complementaridade ou simultaneidade entre a abordagem de produção fordista-taylorista e a de produção flexível, não há na educação escolar divergências entre um modelo de educação a distância fundamentado na centralidade das TICs e um modelo de educação a distância baseados na ideologia do multiculturalismo e na pedagogia das competências. Constata-se que por detrás de um discurso ideológico de respeito às diversidades, desenvolve-se um processo de homogeneização que unem as características próprias da produção fordista às da produção flexível. Assim, de um lado, a EaD efetivamente se caracteriza pela padronização, racionalização, divisão das tarefas e centralização voltadas para um mercado em massa, de outro lado, promove uma suposta consideração das necessidades particulares dos discentes por meio de uma prática político-pedagógica ativista, colocando no centro do processo educativo a distância o aluno como agente ativo da própria aprendizagem, e o tutor como mero incentivador do autodidatismo. Nessa concepção é possível até questionar o não-diretivismo docente do tutor, já que não se trata de um mediador entre aluno e conhecimento, portanto, não diz respeito nem às discussões sobre diretivismo ou nãodiretivismo, mas de uma postura ativista do desenvolvimento das competências que 
míngua a noção de docência. Nesse sentido ainda é possível pensar sobre a denominação de "ensino" a distância, já que uma denominação mais pertinente seria de "aprendizagem" a distância, tal como as formulações da AA e AAD (aprendizagem aberta e aprendizagem aberta a distância) que, aliás, foi desconsiderada na sua implementação no Brasil.

Na realidade o fim último é o mesmo, a unicidade e universalidade. A intenção é a busca de meios educacionais e culturais para homogeneizar a heterogeneidade ou produzir uma heterogeneidade condizente com uma visão de mundo homogênea. $O$ comércio exterior, a mundialização do capital e a globalização cultural são as necessidades iminentes dos países centrais no mundo, a que a educação é convocada - com auxílio dos organismos internacionais como a Unesco e a OCDE - a contribuir com a parte que lhe cabe.

$\mathrm{Na}$ educação a distância, o trabalho docente do tutor é reconfigurado profissionalmente e formativamente, cuja principal consequência é a secundarização do conhecimento e o ensino e aprendizagem de competências, cognitivas e sociais. A educação dos alunos concentra-se no desenvolvimento de habilidades e competências consideradas naturais ou adaptativas, tornando os responsáveis pelo seu desenvolvimento e por suas próprias aprendizagens, cabendo aos tutores a aquisição de novas habilidades no processo de ensino, particularmente, gerenciar administrativamente o processo virtual de ensino-aprendizagem, mediados pelas TICs. Consequentemente, surge um novo profissional da educação, o tutor. $\mathrm{O}$ tutor não é um professor nem mesmo um mediador entre o aluno e o conhecimento, mas uma figura dotada de um vazio inexplicável. A essência do tutor é caracterizada justamente pela ausência de especificidade profissional ou formativa, pois sua qualificação independe de uma legislação profissional própria e de uma formação científico-acadêmica para atuar como tutor em qualquer curso específico, bastando apenas dominar um conjunto de competências entre as quais as "digitais" para ser um "professor bem sucedido".

Todas essas mudanças institucionais na universidade pública estatal instauram mais uma vez o elitismo e dualismo escolar na história do ensino superior no Brasil. Nesse sistema dividem-se os professores. Uns são destinados a capacitar ou gerenciar em condições precárias uma parcela da população com base em pedagogias que negam o conhecimento historicamente construído pela sociedade e a diretividade do professor. Outros dispõem de melhores condições de trabalho e dedicam-se à formação dos alunos nos centros de excelência, notadamente, em cursos presenciais que se prezam pelo conhecimento historicamente construído pela sociedade e se pautam, pela indissociabilidade entre ensino-pesquisa-extensão.

\section{Referências}

ALVES, Giovanni. O novo (e precário) mundo do trabalho: Reestruturação produtiva e crise do sindicalismo. São Paulo. Boitempo, 2000.

ARAÚJO, Ivanildo Amaro. Textos, contextos e intertextos do trabalho pedagógico do(a) professor(a) - mediador(a) no curso PIE/FE -UNB. Tese de doutorado. UNICAMP. Campinas. 2007.

ARAÚJO, Viviane Patrícia Colloca. A multiculturalidade nas políticas educacionais e a formação de professores: Brasil e Portugal. Tese de doutorado. UFSCar. São Carlos. 2009.

ARCE, Alessandra. Educação a distância: "cavalo de tróia" na formação do pedagogo? In: SOUZA, D. D.; FLORESTA, M.G.S.; SILVA JÚNIOR, J.R. (Orgs.). Educação a distância: diferentes abordagens críticas. São Paulo: Xamã, 2010, p. 77-87. 
ARETIO, Lorenzo García. La educación a distância: De la teoria a la práctica. Barcelona: Ariel. 2002.

BELLONI, Maria Luiza, Educação a distância. Campinas, SP: Autores Associados. 2003.

DELLA FONTE, Sandra Soares; LOUREIRO, Robson. Educação escolar e o multiculturalismo intercultural: crítica a partir de Simone de Beauvoir. In: Pro-Posições, Campinas, v. 22, n. 3 (66), p. 177-193, set./dez. 2011.

DELORS, Jacques. Educação: Um tesouro a descobrir. São Paulo, Cortez, 1998.

DUARTE, Newton. Concepções afirmativas e negativas sobre o ato de ensinar. In: Cadernos CEDES. Campinas, v.19, n.44. abr. 1998.

FAURE, Edgar. Aprender a Ser. Lisboa. Bertrad, Difusão Européia do livro, 1974.

FURQUIM, L. A.C.V. O papel pedagógico do tutor na EaD: Uma abordagem bibliométrica baseada no Banco de Teses da Capes. Dissertação de mestrado. Universidade Federal de São Carlos, São Carlos/SP, 2010.

HALL, Stuart. Da diáspora: Identidades e Mediações Culturais. Belo Horizonte: Editora UFMG, 2009.

PETERS, Otto. Duas mudanças estruturais na educação a distância: industrialização e digitalização. São Leopoldo-RS, 2001.

Didática do ensino a distância: experiências e estágio da discussão numa visão internacional. São Leopoldo-RS: Ed. Unisinos, 2003.

SACRISTÁN, José Gimeno (et al). Educar por Competências: O que há de novo? Porto Alegre: Artmed, 2011.

SILVA JÚNIOR, J. R; FERRETTI, C. J. O institucional, a organização e a cultura da escola. São Paulo: Xamã, 2004.

SILVA, Tomaz Tadeu da. Documentos de Identidade: Uma introdução às teorias do currículo. Belo Horizonte, Autêntica, 2005.

ZIEDE, Mariangela Kraemer Lenz. A construção da função dos tutores no âmbito do curso de graduação em pedagogia - Licenciatura na modalidade a distância Universidade Federal do Rio Grande do Sul. Dissertação de mestrado. Universidade Federal do Rio Grande do Sul. Porto Alegre. 2008.

Recebido em julho-12

Aprovado em fevereiro-13

Notas

\footnotetext{
${ }^{1}$ João dos Reis Silva Júnior - Doutor em História e Filosofia da Educação pela PUC-SP, com pós-doutorado em Sociologia pela Unicamp e em Economia pela USP. Professor da UFSCar. E-mail: joaodosreissilvajr@gmail.com

2 Tânia Barbosa Martins - Doutoranda em Educação pela UFSCar. Bolsista FAPESP. E-mail: taniabmartins@yahoo.com.br
} 